Fluctuating dementia and rhinorrhoea

Sir,

CSF rhinorrhoea is a common condition which is usually due to trauma, congenital malformation, tumour, or spontaneous. Nontraumatic CSF rhinorrhoea is rare; there have been previous case reports of this secondary to colloid cyst of the third ventricle. . $^{1,2}$ Aetiologically such non-traumatic CSF leaks are classified in the high pressure group described by Ommaya. ${ }^{3}$ It has been proposed that the CSF leak acts as a safety valve, preventing the development of raised intracranial pressure, the leak allowing the tumour to grow while remaining clinically silent.

A 79-year-old woman, resident at a local nursing home, was admitted via Neurology outpatients. She was normally unable to walk, incontinent of urine, and fully dependent on nursing staff for normal daily activities. It was noted that after a minor fall she developed a profuse watery nasal discharge following which, over a period of weeks, she became rational, lucid, able to read and write, and regained urinary continence. She would then slowly revert to her former self, until another bout of rhinorrhoea, whence she would again improve, the above cycle of events repeating itself several times before she was seen in our out-patients clinic. On examination she was wheelchair-bound, had an indwelling urinary catheter, but could move all limbs spontaneously. Reflexes were brisk but symmetrial, with bilateral extensor plantar responses. Neuropsychological assessment revealed severely impaired cognitive function, with a WAIS-R IQ of 64 (predicted 98), and gross impairment of memory function such that the memory quotient could not be calculated.

A brain CT scan, with contrast (figure), demonstrated a benign looking mass in the fourth ventricle, causing considerable hydrocephalus. A ventriculo-peritoneal shunt was inserted, following which she became self-caring, and regained urinary continence. A repeat scan one week post-operatively showed the shunt in the right lateral ventricle, ventricles being of normal size. She was able to mobilise with the help of a zimmer frame, and discharged back to her nursing home. Two months later repeat neuropsychology yielded a verbal IQ of 91 , not significantly below predicted. Her memory quotient of 114 was higher than her predicted IQ, scores on the majority of subtests falling above the mean for the age group. She continues to make excellent progess and is now walking unaided one year post-discharge.

Our patient was unfit for a major operative procedure and shunt insertion provided a satisfactory outcome. This case illustrates the clinical importance of cerebrospinal rhinorrhoea as a clinical sign, and the importance of recognising it in the differential diagnosis of vasomotor rhinitis. ${ }^{4}$

A WOOLLONS

JE REES

VA BRADLEY

Hurstwood Park Neurological Centre, Princess Royal Hospital, Haywards Heath, W Sussex RH16 4EX, UK

Correspondence to Dr A Woollons, 18 Bennett Road, Kemp Town, Brighton BN2 5JL, UK

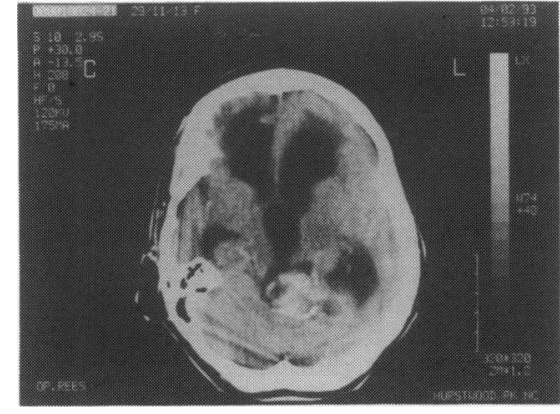

Figure Brain CT scan showing benignlooking mass in the fourth ventricle

Causes of rhinorrhoea and dementia

- old age 'senile rhinorrhoea'

- CSF rhinorrhoea due to: trauma: fracture cribriform plate high pressure leak: tumour (direct/indirect) hydrocephalus (obstructive/ communicating)

normal pressure leak: osteomyelitis focal atrophy (olfactory intrasellar)

1 Williams PC, English GM, Edgar RE. Colloid cyst causing rhinorrhoea. Surg Neurol 1980; 14: cyst causi.

2 Kane PJ, Mendelow AD, Keogh AJ, Symon L. Cerebrospinal rhinorrhoea associated with colloid cyst. Br $\mathcal{F}$ Neurosurg 1991; 5: 317-20.

3 Ommaya AK, Di Chiro G, Baldwin M, Pennybacker JB. Non-traumatic cerebrospinal fluid rhinorrhoea. I Neurol Neurosurg Psychiatry 1968; 31: 214-25.

4 Brockbank MJ, Veitch DY, Thomson HG. Cerebrospinal fluid in the rhinitis clinic. $f$ Larnygol Otol 1989; 103: 281-3.

\section{A negative skin biopsy for malignancy does not exclude the possibility of subsequent fatal disease}

Sir

Lentigo maligna (LM) is a benign melanocytic skin lesion that affects the elderly population. It is widely regarded as having an excellent prognosis and as such, is often ignored by both patient and physician alike We report a fatal case of regressed primary lentigo maligna melanoma (LMM), which is the invasive counterpart of LM. Since the risk of progression from $L M$ to $L M M$ is considered small and because they present in the elderly as a large lesion in a cosmetically difficult area, treatment tends to be less aggressive than in other forms of melanoma The absence of invasion on histology seemingly further justifies a conservative approach.

In March 1988 an 85-year-old female presented with LM on her right cheek. In March 1993 she was re-referred because the lesion had gradually increased in size, shape, and pigmentation. Histology of the lesion from a biopsy taken at this time showed evidence of a largely regressed melanocytic lesion. Four months later the patient was admitted to hospital as an emergency in status epilepticus. Investigation revealed widespread malignant disease. At autopsy multiple melanotic deposits were seen within the lungs and brain which on histology had the appearance of metastatic spindle-cell malignant melanoma. No other primary site for melanoma was identified other than the lesion on the right cheek.

The histological appearances of the initial biopsy from the lesion on the right cheek were only that of pigmentary incontinence, fibrosis, and inflammation. Although no invasive malignancy was identified histologically the appearance was consistent with tumour regression. The latter is a recognised phenomenon in the natural history of any melanoma although there is debate about its prognostic significance. ${ }^{1}$ In LMM spindle cells are the most common invasive morphological manifestation. ${ }^{2}$ Accordingly, the histology of the pulmonary metastases in this case was entirely consistent with LMM being the primary lesion.

Progression from LM to LMM may take up to 50 years. ${ }^{3}$ However, once LMM has developed, death due to metastases may be less common than in other types of melanoma. ${ }^{4}$ Preferred treatment is wide local excision. It is now recognised that a primary malignant melanoma can occasionally regress and that widespread metastases and death can subsequently occur. This sequence of events is, however, best described for LMM.

JOHN JACOB CHRISTOPHER A AUSTIN Royal Hallamshire Hospital, Sheffield S10 2fF, UK DAVID N SLATER Department of Histopathology, Rotherham District General Hospital, Rotherham S60 2UD, UK

Correspondence to CA Austin

1 McGovern VJ, Shaw HM, Milton GW. Prognosis in patients with thin malignant melanoma: influence of regression. Histopathology 1983; 7 673-680.

2 Sondergaard K. Histological type and biological behaviour of primary cutaneous malignan melanoma. Virchows Arch $A$ 1983; 401 $315-31$

3 Weinstock MA, Sober AJ. The risk of progression of lentigo maligna to lentigo malign melanoma. Br F Dermatol 1987; 116: 303-10. 4 McGovern VJ, Shaw HM, Milton GW, et al. Is malignant melanoma arising in a Hutchinson's melanotic freckle a separate disease entity? Histopathology 1980; 4: 235-42.

5 Clark WH, Mihm MC, Jr. Lentigo maligna and lentigo maligna melanoma. Am $\mathcal{F}$ Pathol 1969 ; 53: $39-67$.

\section{Lentigo maligna}

- benign melanocytic skin lesion

- affects the elderly

- usually excellent prognosis

- rarely progresses to lentigo maligna melanoma 